\title{
Antihypertensive Drugs and Insulin Resistance in Obesity
}

Key words: Hypertension, calcium channel blockers, dehydroepiandrosterone, insulin resistance

Obesity increases the risk for hypertension. Several studies have demonstrated that weight gain raises blood pressure and weight loss reduces blood pressure. The mechanisms leading to hypertension in obese individuals are not completely understood, however the primary metabolic abnormality is insulin resistance and this has been implicated in both the hemodynamic and metabolic consequences of obesity (1). Other proposed mechanisms of obesity-related hypertension are activation of renin-angiotensin system and increased sympathetic nervous system activity.

Formerly it is reported that the short-acting calcium channel blocker, nifedipine, deteriorates insulin resistance via acceleration of the sympathetic nervous system (2) in contrast to angiotensin-converting enzyme (ACE) inhibitor (3) and that diltiazem and verapamil have no effect on insulin resistance (4). Regarding therapeutic guidelines for hypertension with diabetes from the Japan Hypertension Association and Japan Diabetes Society, calcium channel blocker is one of the first choice treatments for hypertension with diabetes. In contrast, calcium channel blocker is not the first choice treatment in the Guidelines from the American Diabetes Association, which is based on the results of IDNT.

However, the long-acting calcium channel blockers, amlodipine and nitrendipine, improve glucose tolerance (5), reduce fasting and glucose-stimulated serum insulin levels, increase serum DHEA-S and androstenedione levels, and decrease circulating cortisol $(6,7)$ and manidipine, improves insulin resistance as assessed by glucose clamp technique (8). These findings have been confirmed by the authors in hypertensive obese patients (9).

An elevated intracellular calcium level and its suppression effect of insulin have been reported in obese subjects (10) and an increased intracellular calcium level seems to be associated with insulin resistance. Therefore, decreased intracellular $\mathrm{Ca}^{2+}$ following a long-acting calcium channel blocker treatment might be possibly related to insulin resistance (11).

The authors suggested that reduced dehydroepiandrosterone (DHEA) and DHEA-sulfate level in hypertensive obese patients was caused by the shift in adrenal steroid synthesis. Although the sex ratio was similar among the groups in this paper, the finding of a sex-based disparity in DHEA-S and DHEA responses to insulin reduction suggests that the metabolism of these steroids may be regulated differently in men than in women (12) and these data render interpretation difficult.

DHEA and DHEA-S are the most abundant adrenal steroids in man. The metabolism of these hormones is unique and the serum concentration of DHEA-S in human plasma is about 300 times higher than that of DHEA and 20 times higher than that of any other steroid hormone. DHEA is considered to be a weak androgen and its concentration has a greater diurnal variation than DHEA-S. Peak serum DHEA and DHEA-S levels occur around age twenties and decrease gradually to $5 \%$ of these peak values by the age of ninety. Since Yen et al reported an antiobesity effect of DHEA in an experimental animal model (13), many other studies have disclosed a variety of other potential physiological effects of DHEA. In particular, the antidiabetic effect of DHEA has been well evaluated. DHEA reduces the hyperglycemia and/ or hyperinsulinemia of diabetic mice and obese Zucker rats, suppresses the elevated hepatic glucose-6-phosphatase and fructose-1,6-bisphosphatase activities, and increases tissue sensitivity of insulin in aged rats $(14,15)$. In the obese group, DHEA-S levels showed a significant positive relationship with insulin (16). The authors showed insulin, DHEA, and DHEA-S were decreased in two months after the administration of calcium channel blocker in both this paper and in another trial (17). It is, however, difficult to conclude whether insulin regulated DHEA and DHEA-S or these steroids regulate the insulin level from the data. Further evaluation will be needed because the correlation between DHEA/DHEA-S and insulin is still controversial $(18,19)$.

TNF- $\alpha$ plays a major role in the pathogenesis of obesityinduced insulin resistance. Several studies have demonstrated that the production of TNF- $\alpha$ by adipose tissue increases in obesity-induced insulin resistant states. Complete absence of the TNF gene or both of its receptors results in significant improvement in insulin sensitivity in mice with dietary, hypothalamic, or genetic obesity. Nicardipine, amlodipine and manidipine significantly inhibit TNF-alpha production in mice at doses of more than one or ten times higher than those used clinically (20) and DHEA treatment reduces body weight and serum TNF-alpha independently, and both may ameliorate insulin resistance in obese Zucker fatty rats (21). Measuring the serum TNF level of patients may be interesting pre and post treatment with calcium channel blocker in this relevant trial.

Sympathetic nervous activity is hyperactive in obesity and furthermore hyperinsulinemia increases sympathetic nerve tone. Cilnidipine treatment did not significantly increase serum norepinephrine levels, which suggests that cilnidipine 
improves insulin resistance, possibly due to its exerting a vasodilatory action without stimulating sympathetic nervous activity (22). Alvarez et al reported that sympathetic nerve activity is elevated in men with visceral obesity which is consistent with the idea that abdominal visceral fat is an important adipose tissue depot linking obesity with sympathetic neural activation in humans (23). Although the authors did not show the leptin level, it may be also interesting because leptin has an important link between obesity, sympathetic activity, and hypertension (24).

From these findings, long acting calcium channel blocker can be one of the first choice treatments for hypertensive obese patients, which the authors showed in this trial.

Koji MUKASA, MD

Ito Hospital, 4-3-6 Jingumae, Shibuya-ke, Tokyo 150-8308

\section{References}

1) Modan M, Halkin H, Almog S, et al. Hyperinsulinemia. A link between hypertension obesity and glucose intolerance. J Clin Invest 75: 809817, 1985.

2) Giugliano D, Torella R, Cacciapuoti F, Gentile S, Verza M, Varricchio M. Impairment of insulin secretion in man by nifedipine. Eur J Clin Pharmacol 18: 395-398, 1980.

3) Lithell HO, Pollare T, Berne C. Insulin sensitivity in newly detected hypertensive patients: influence of captopril and other antihypertensive agents on insulin sensitivity and related biological parameters. J Cardiovasc Pharmacol 15 Suppl 5: S46-52, 1990.

4) Berne C, Pollare T, Lithell H. Effects of antihypertensive treatment on insulin sensitivity with special reference to ACE inhibitors. Diabetes Care 14 Suppl 4: 39-47, 1991.

5) Harano Y, Kageyama A, Hirose J, et al. Improvement of insulin sensitivity for glucose metabolism with the long-acting Ca-channel blocker amlodipine in essential hypertensive subjects. Metabolism 44: 315319, 1995.

6) Beer NA, Jakubowicz DJ, Beer RM, Nestler JE. The calcium channel blocker amlodipine raises serum dehydroepiandrosterone sulfate and androstenedione, but lowers serum cortisol, in insulin-resistant obese and hypertensive men. J Clin Endocrinol Metab 76: 1464-1469, 1993.

7) Beer NA, Jakubowicz DJ, Beer RM, Arocha IR, Nestler JE. Effects of nitrendipine on glucose tolerance and serum insulin and dehydroepiandrosterone sulfate levels in insulin-resistant obese and hypertensive men. J Clin Endocrinol Metab 76: 178-183, 1993.

8) Iimura $\mathrm{O}$, Shimamoto $\mathrm{K}$, Masuda A, et al. Effects of a calcium channel blocker, manidipine, on insulin sensitivity in essential hypertensives. J Diabetes Complications 9: 215-219, 1995.

9) Ueshiba H, Miyachi Y. Effects of the long-acting calcium channel blockers, amlodipine, manidipine and cilnidipine on steroid hormones and insulin resistance in hypertensive obese patients. Intern Med 43: 561-565, 2004.

10) Draznin B, Sussman KE, Eckel RH, Kao M, Yost T, Sherman NA Possible role of cytosolic free calcium concentrations in mediating insulin resistance of obesity and hyperinsulinemia. J Clin Invest 82: 1848-1852, 1988.

11) Suzuki M, Kanazawa A, Hasegawa M, Harano Y. Improvement of insulin resistance in essential hypertension by long-acting $\mathrm{Ca}$ antagonist benidipine. Clin Exp Hypertens 21: 1327-1344, 1999.

12) Beer NA, Jakubowicz DJ, Beer RM, Nestler JE. Disparate effects of insulin reduction with diltiazem on serum dehydroepiandrosterone sulfate levels in obese hypertensive men and women. J Clin Endocrinol Metab 79: 1077-1081, 1994.

13) Yen TT, Allan JA, Pearson DV, Acton JM, Greenberg MM. Prevention of obesity in Avy/a mice by dehydroepiandrosterone. Lipids 12: 409413, 1977.

14) Aoki K, Saito T, Satoh $S$, et al. Dehydroepiandrosterone suppresses the elevated hepatic glucose-6-phosphatase and fructose-1, 6-bisphosphatase activities in C57BL/Ksj-db/db mice: comparison with troglitazone. Diabetes 48: 1579-1585, 1999.

15) Mukasa K, Kanesiro M, Aoki K, et al. Dehydroepiandrosterone (DHEA) ameliorates the insulin sensitivity in older rats. J Steroid Biochem Mol Biol 67: 355-358, 1998.

16) Al-Harithy RN. Dehydroepiandrosterone sulfate levels in women. Relationships with body mass index, insulin and glucose levels. Saudi Med J 24: 837-841, 2003.

17) Ueshiba H, Tsuboi K, Miyachi Y. Effects of amlodipine on serum levels of adrenal androgens and insulin in hypertensive men with obesity. Horm Metab Res 33: 167-169, 2001.

18) Jedrzejuk D, Medras M, Milewicz A, Demissie M. Dehydroepiandrosterone replacement in healthy men with age-related decline of DHEAS: effects on fat distribution, insulin sensitivity and lipid metabolism. Aging Male 6: 151-156, 2003.

19) Kawano H, Yasue H, Kitagawa A, et al. Dehydroepiandrosterone supplementation improves endothelial function and insulin sensitivity in men. J Clin Endocrinol Metab 88: 3190-3195, 2003.

20) Fukuzawa M, Satoh J, Ohta $S$, et al. Modulation of tumor necrosis factor-alpha production with anti-hypertensive drugs. Immunopharmacology 48: 65-74, 2000.

21) Kimura M, Tanaka S, Yamada Y, Kiuchi Y, Yamakawa T, Sekihara H. Dehydroepiandrosterone decreases serum tumor necrosis factor-alpha and restores insulin sensitivity: independent effect from secondary weight reduction in genetically obese Zucker fatty rats. Endocrinology 139: 3249-3253, 1998.

22) Yagi $S$, Goto $S$, Yamamoto $T$, Kurihara $S$, Katayama S. Effect of cilnidipine on insulin sensitivity in patients with essential hypertension. Hypertens Res 26: 383-387, 2003.

23) Alvarez GE, Beske SD, Ballard TP, Davy KP. Sympathetic neural activation in visceral obesity. Circulation 106: 2533-2536, 2002.

24) Hall JE, Hildebrandt DA, Kuo J. Obesity hypertension: role of leptin and sympathetic nervous system. Am J Hypertens 14: 103S-115S, 2001. 